Pacific Journal of Mathematics

SYMMETRIC SUBLATTICES OF A NOETHER LATTICE 


\title{
SYMMETRIC SUBLATTICES OF A NOETHER LATTICE
}

\author{
Michael E. Detlefsen
}

\begin{abstract}
In this note we investigate questions about partitions of positive integers arising from multiplicative lattice theory and prove that the sublattice of $R L\left(A_{i}\right)\left(A_{1}, \cdots, A_{k}\right.$ is a prime sequence in a local Noether lattice) generated by the elementary symmetric elements in the $A_{i}$ 's is a $\pi$-lattice.
\end{abstract}

o. Introduction. If $A_{1}, A_{2}, \cdots, A_{k}$ is a prime sequence in $L$, a local Noether lattice, then the multiplicative sublattice it generates is isomorphic to $R L_{k}$, the distributive local Noether lattice with altitude $k$. We denote this sublattice of $L$ by $R L\left(A_{i}\right)$. In $R L\left(A_{i}\right)$, every element is a finite join of products $A_{1}^{r_{1}} A_{2}^{r_{2}} \cdots A_{k}^{r_{k}}$ for $\left(r_{1}, \cdots, r_{k}\right)=$ $\left(r_{i}\right)$ a $k$-tuple of nonnegative integers. Minimal bases for an element, $T$, in $R L\left(A_{i}\right)$ are unique and determined by the exponent $k$-tuples of the elements in the minimal base for $T$. We examine the sublattice of $L$ generated by the elementary symmetric elements in the prime sequence $A_{1}, \cdots, A_{k}$. This multiplicative sublattice is a $\pi$-domain (Theorem 7.1).

Unless otherwise stated, all $k$-tuples will be nonnegative integers. A $k$-tuple $\left(r_{i}\right)$ is monotone if and only if $r_{i} \geqq r_{i+1}$ for $1 \geqq i>k$. $\left(r_{i}\right)=\left(s_{i}\right)$ and $\left(r_{i}\right)+\left(s_{i}\right)$ refer to componentwise equality and addition respectively. $\left(r_{i}\right) \geqq_{p}\left(s_{i}\right)$ means $r_{i} \geqq s_{i}$ for $i=1, \cdots, k$. We write $\left(r_{i}\right) \geqq_{l}\left(s_{i}\right)$ to mean the first nonzero entry in $\left(r_{i}-s_{i}\right)$ is strictly positive (lexicographic order). If $\left(e_{i}\right)$ is a $k$-tuple we write $e_{i}^{*}$ for $\sum_{j=i}^{k} e_{j}$ and $e_{i}^{* *}$ for $\sum_{j=i}^{k} e_{j}^{*}$. Throughout this note $A_{1}, \cdots, A_{k}$ is a prime sequence in $L$ and $R L\left(A_{i}\right)$ is the multiplicative sublattice it generates.

1. The symmetric sublattice. If $T$ is a principal element in $R L\left(A_{i}\right)$ and $g$ is in $S_{k}$, the permutation group on $1, \cdots, k$, we define $T_{g}\left(T^{g}\right)$ to be the principal element in $R L\left(A_{i}\right)$ obtained by replacing $A_{i}^{t(i)}$ by the factor $A_{g(i)}^{t(i)}\left(A_{i}^{t(g(i))}\right)$ in $T$ for each $i$ from 1 to $k$. If $C_{1} \vee \cdots \vee C_{p}$ is a minimal base for $C$ in $R L\left(A_{i}\right)$, then $C_{g}=$ $\left(C_{1}\right)_{g} \vee \cdots \vee\left(C_{p}\right)_{g} . \quad C^{g}$ is defined similarly. Note that for each $g$ in $S_{k}$ and for $C$ in $R L\left(A_{i}\right),\left(C_{g}\right)^{g}=\left(C^{g}\right)_{g}=C$. Hence $C_{g}=C^{g^{-1}}$. An element $C$ in $R L\left(A_{i}\right)$ is a symmetric element if and only if $C_{g}=C$ for each $g$ in $S_{k}$.

THEOREM 1.1. The set of all symmetric elements in $R L\left(A_{i}\right)$ forms a multiplicative sublattice of $R L\left(A_{i}\right)$ which is closed under residuation. 
Proof. We show that $F_{g}$, the set of elements fixed by the map $\dot{\rho}$ from $R L\left(A_{i}\right)$ to $R L\left(A_{i}\right)$ defined $C \stackrel{\phi}{\mapsto} C^{g}$ for $g$ in $S_{k}$ is a residuated multiplicative lattice. For then the set of symmetric elements which is the intersection of all of the $F_{g}$ 's for $g$ in $S_{k}$ is also a multiplicative sublattice.

Let $g$ be any permutation in $S_{k}$ and $\phi$ be defined as above. $\phi$ is well defined and preserves join by definition. Since $\left(C_{g}\right)^{g}=\left(C^{g}\right)_{g}=C$ for each $C$ in $R L\left(A_{i}\right), \phi$ is a bijection.

Let $B=\Pi A_{i}^{b_{i}}$ and $C=\Pi A_{i}^{c_{i}}$ be principal elements in $R L\left(A_{i}\right)$. Then $(B C)^{g}=\Pi A_{g-1(i)}^{b_{i}+c_{i}}=\Pi A_{g-1(i)}^{b_{i}} \cdot \Pi A_{g-1(i)}^{c_{i}}=B^{g} \cdot C^{g}$ and $(B \wedge C)^{g}=$ $\left(\Pi \mathrm{A}_{i}^{\max \left(b_{i}, c_{i}\right)}\right)^{g}=\Pi A_{g^{-1}(i)}^{\max \left(b_{i}, c_{i}\right)}=\Pi A_{g^{-1}(1)}^{b_{i}} \wedge \Pi A_{g^{-1}(i)}^{c_{i}}=B^{g} \wedge C^{g}$. Since elements in $R L\left(A_{i}\right)$ are joins of principal elements and multiplication and meet distribute over join, $\phi$ preserves products and meet.

Finally, the fact that $\phi$ preserves residuals and that $F_{g}$ is a multiplicative sublattice of $R L\left(A_{i}\right)$ readily follows from the fact that $\dot{\rho}$ is a multiplicative lattice isomorphism.

REMARK. If $B$ is a principal element in $R L\left(A_{i}\right)$ such that $B^{g}=B$, then $B$ is a principal element in $F_{g}$. However, $F_{g}$ contains enough principal elements to make it a Noether lattice only if $g$ is the identity in $S_{k}(\operatorname{cf} \S 7)$ for $k>1$.

2. Elementary symmetric elements. For $t=1, \cdots, k, a_{t}$, the $t$ th elementary symmetric element in $A_{1}, \cdots, A_{k}$ is the join of all products of $A_{1}, \cdots, A_{k}$ with $t$ distinct factors. In this section we investigate the chain $0<a_{k}<\cdots<a_{1}<I$ of elementary symmetric elements in $R L\left(A_{i}\right)$.

We say the weight of a principal element in $R L\left(A_{i}\right)$ is the maximum of its exponents. If $J$ is a $t$-tuple $\left(i_{1}, \cdots, i_{t}\right)$ with $i_{j}<i_{j+1}$ and $t \leqq k$ then we denote by $(J)$ the set of all $(k-t)$-tuples $\left(j_{1}, \cdots, j_{k-t}\right)$ such that $\left\{j_{1}, \cdots, j_{k-t}\right\} \cap\left\{i_{1}, \cdots, i_{t}\right\}$ is empty.

THEOREM 2.1. The elementary symmetric elements together with 0 and I form a sublattice closed under residuation. In particular

$$
\left(a_{t}: a_{p}\right)= \begin{cases}I & \text { if } t \leqq p \\ a_{t} & \text { if } t>p .\end{cases}
$$

Proof. From [8, p. 84] we have for $t>p$

$$
\left(a_{t}: a_{p}\right)=\vee\left(J_{1}\right) \vee\left(J_{2}\right) \vee \cdots \vee\left(J_{q}\right)\left(A_{i_{1}} \cdot A_{i_{2}} \cdots A_{i_{s}} \wedge \cdots \wedge A_{q_{1}} \cdots A_{q_{s}}\right)
$$

where there are $C(k, p)$ (the binomial coefficient) join symbols each having indices in $\left(J_{1}\right), \cdots,\left(J_{q}\right)$ for $J_{i}$ one of the $C(k, p)$ ordered $p$ - 
tuples which can be chosen from $\{1, \cdots, k\}$. Each intersection has weight one and by symmetry, $\left(a_{t}: a_{p}\right)=a_{r}$ for some $r$. Since $a_{t} \leqq$ $\left(a_{t}: a_{p}\right)$ we only need show that $\left.a_{t-1} \not a_{t}: a_{p}\right)$.

Let $A_{i_{1}} \cdots A_{i_{t-1}}$ be any element in the minimal base for $a_{t-1}$ and $A_{i_{1}} \cdots A_{i_{p}}$ be the product of the first $p$ of these $(p \leqq t-1)$. Then their product $A_{i_{1}}^{2} \cdots A_{i_{p}}^{2} \cdots A_{i_{t-1}}$ is an element which is not less than or equal to any element in the minimal base for $a_{t}$. Hence $a_{t-1} \equiv\left(a_{t}: a_{p}\right)$.

REMarK. From the Reciprocity Theorem [9, Theorem 5.1] we can define a multiplication on the chain of elementary symmetric elements by $\left(a_{t}: a_{p}\right) \geqq a_{s}$ if and only if $a_{t} \geqq a_{p} \cdot a_{s}$, i.e., $a_{p} a_{s}=a_{\max \{p, s\}}$. This new multiplication makes every element in the chain idempotent and the order becomes $a \leqq b$ if and only if $a \cdot b=a$ for nonzero elements different from $I$.

3. The minimal base for $\pi a_{i}^{e_{i}}:$ majorization. In this section we determine the minimal base for a product of the elementary symmetric elements in $R L\left(A_{i}\right)$. We first dispense with the powers of the $a_{2}$.

Lemma 3.1. For $t<k, a_{t}^{e}$ is the join of all powers of the $A_{i}$ 's whose exponents are bounded above by $e$ and whose exponent sum is te. $a_{k}^{e}=A_{1}^{e} \cdots A_{k}^{e}$.

Proof. For $k>1$, let $\left(k_{i}\right)$ be any $k$-tuple of nonnegative integers summing to te and bounded above by $e$. By symmetry we assume $\left(k_{i}\right)$ is monotone. There are at least $t$ nonzero $k_{i}$ 's no more than $t$ of which are equal to $e$. Let

$$
v_{i}=\left\{\begin{array}{ll}
k_{i}-1 & 1 \leqq i \leqq t \\
k_{i} & t<i \leqq k
\end{array} \text { and } \quad w_{i}= \begin{cases}1 & 1 \leqq i \leqq t \\
0 & t<i \leqq k\end{cases}\right.
$$

Then $\left(v_{i}\right)+\left(w_{i}\right)=\left(k_{i}\right)$ and by induction $\Pi A_{i}^{v_{i}}$ and $\Pi A_{j}^{w_{i}}$ are elements in the minimal base for $a_{t}^{e-1}$ and $a_{t}$ respectively. Hence their product which has $\left(k_{i}\right)$ as its exponent $k$-tuple is in the minimal base for $a_{t}^{e}$. The converse follows by writing down a product in $a_{t}^{e}$ and observing the conditions hold.

LeMma 3.2. $\Pi A_{j}^{r_{j}}$ is in the minimal base for $\Pi a_{i}^{e_{i}}$ if and only if there is a nonnegative $k \times k$ matrix whose ith row sum is $i e_{i}$, whose ith row is bounded above by $e_{i}$, and whose $j$ th column sum is $r_{j}$. 
Proof. If $\Pi A_{j}^{r_{j}}=C_{1} \cdots C_{k}$ where $C_{i}$ is in the minimal base for $a_{i}^{e_{i}}$, then $C_{i}=\Pi A_{j}^{r_{i j}}$ where $r_{i j} \leqq e_{i}$ and $\sum_{j} r_{i j}=i e_{i}$. Then $\Pi_{i} C_{i}=$ $\Pi_{j} A_{j}^{r_{j}}$ where $r_{j}=\sum_{i} r_{i j}$ for $j=1, \cdots, k$. $\left(r_{i j}\right)$ is the desired matrix. The converse follows easily.

The existence of the matrix described in Lemma 3.2 is determined by the following generalization of the Gale-Ryser theorem on $(0,1)$ matrices [7, p. 63].

DEFINITION 3.3. If $\mathfrak{M}=\left(e_{1}, e_{2}, \cdots, e_{k}\right)$ is a $k$-tuple of nonnegative integers, an M-matrix is a matrix of nonnegative integers with $k$ rows whose $i$ th row entries are bounded above by $e_{i} \cdot \mathrm{A} k \times t \mathfrak{M}$ matrix is maximal with row sums $\left(f_{i}\right)$ if each row is maximal in the lexicographic order of $t$-tuples.

In Lemma $3.4\left(r_{j}^{\prime}\right)$ is the monotone permutation of $\left(r_{j}\right)$. If the condition of the lemma holds we say $\left(r_{j}\right)$ is majorized by $\left(s_{j}\right)$ and write $\left(r_{j}\right) \prec\left(s_{j}\right)$.

LEMmA 3.4. If $\left(t_{i j}\right)$ is the maximal $k \times t$ M-matrix with row sums $\left(f_{i}\right)$ and column sums $\left(s_{j}\right)$, then there exists an $\mathfrak{M}$-matrix $\left(r_{i j}\right)$ with column sums $\left(r_{j}\right)$ if and only if $\sum_{1}^{\nu} r_{j}^{\prime} \leqq \sum_{1}^{\nu} s_{j}$ for $\nu=1, \cdots, t-1$ with equality when $\nu=t$.

Proof. The proof follows mutatis mutandus from [5, p. 1030].

Lemmas 3.2 and 3.4 allow us to characterize the elements in the minimal base for $\Pi a_{i}^{e_{i}}$.

THEOREM 3.5. The minimal base for $\Pi a_{i}^{e^{i}}$ in $R L\left(A_{i}\right)$ is the join of all products of the $A_{i}$ 's whose exponent k-tuples are majorized by $\left(e_{i}^{*}\right)$.

Proof. The maximal $k \times k\left(e_{i}\right)$-matrix with row sums $\left(i e_{i}\right)$ has column sums $e_{i}^{*}$. Hence $\left(r_{i}\right) \prec\left(e_{i}^{*}\right)$ if and only if there exists an $\left(e_{i}\right)$-matrix with row sums $\left(i e_{i}\right)$ and column sums $\left(r_{i}\right)$. But this holds if and only if $\Pi A_{i}^{r_{i}}$ is an element in the minimal base for $\Pi a_{i}^{e_{i}}$.

REMARK. For $k \leqq 3$ we have determined that the product $\Pi a_{i}^{e_{i}}$ has as a minimal base the join of all products of the $A_{i}$ 's whose exponent $k$-tuples are bounded above by $e_{1}^{*}$, bounded below by $e_{k}$, sum to $\sum i e_{i}$ and whose breadth is less that or equal to $\sum_{1}^{k}\left(t k-t^{2}\right) e_{t}$. The breadth of $\Pi A_{i}^{r_{i}}$ is $\sum_{i<j}\left|r_{i}-r_{j}\right|$. However this characterization does not hold for $k>3$.

4. $P\left(a_{1}, a_{2}, \cdots, a_{k}\right)$, A multiplicative sublattice. Let $P\left(a_{1}, \cdots\right.$, $\left.a_{k}\right)=P\left(a_{i}\right)$ be the set of all finite joins of products of the elementary 
symmetric elements in $A_{1}, \cdots, A_{k}$. We will show that this set is the multiplicative sublattice generated by $a_{1}, \cdots, a_{k}$.

If $\left(u_{i}\right)$ and $\left(v_{i}\right)$ are $k$-tuples we define the distance between them as $d\left(\left(u_{i}\right),\left(v_{i}\right)\right)=\sum_{i}\left|u_{i}-v_{i}\right|$. The lemma which follows will aid us in identifying the minimal base for the meet of two products to the $a_{i}$ 's.

LEMMA 4.1. Let $\left(u_{i}\right)$ and $\left(v_{i}\right)$ be k-tuples majorized by monotone k-tuples $\left(r_{i}\right)$ and $\left(s_{i}\right)$, respectively. Then if $w_{i}=\max \left(u_{i}, v_{i}\right)$ for $i=1, \cdots, k$

(1) $d\left(\left(u_{i}\right),\left(v_{i}\right)\right)=\left|r_{1}^{*}-s_{1}^{*}\right|$ if and only if $w_{1}^{*}=\max \left(r_{1}^{*}, s_{1}^{*}\right)$.

(2) $d\left(\left(u_{i}\right),\left(v_{i}\right)\right) \geqq\left|r_{1}^{*}-s_{1}^{*}\right|$.

(3) $d\left(\left(u_{i}\right),\left(v_{i}\right)\right)>\left|r_{1}^{*}-s_{1}^{*}\right|$ implies there exist k-tuples $\left(\bar{u}_{i}\right)$ and $\left(\bar{v}_{i}\right)$ such that $\left(w_{i}\right) \geqq_{p}\left(\max \left(\bar{u}_{i}, \bar{v}_{i}\right)\right)$ and $d\left(\left(\bar{u}_{i}\right),\left(\bar{v}_{i}\right)\right)=\left|r_{1}^{*}-s_{1}^{*}\right| \cdot$

Proof. (1) $2 \cdot w_{1}^{*}=\sum_{i}\left(u_{i}+v_{i}+\left|u_{i}-v_{i}\right|\right)=r_{1}^{*}-s_{1}^{*}+\left|r_{1}^{*}-s_{1}^{*}\right|=$ $2\left(\max \left(r_{1}^{*}, s_{1}^{*}\right)\right)$ if and only if $\sum\left|u_{i}-v_{i}\right|=\left|r_{1}^{*}-s_{1}^{*}\right|$ since for any two integers $a, b 2(\max (a, b))=a+b+|a-b|$.

(2) $\left|r_{1}^{*}-s_{1}^{*}\right|=\left|u_{1}^{*}-v_{1}^{*}\right|=\left|\sum_{i}\left(u_{i}-v_{i}\right)\right| \leqq \sum_{i}\left|u_{i}-v_{i}\right|=d\left(\left(u_{i}\right),\left(v_{i}\right)\right)$.

(3) $d\left(\left(u_{i}\right),\left(v_{i}\right)\right)|>| u_{1}^{*}-v_{1}^{*} \mid$ implies there exist indices $i_{1}$ and $i_{2}$ such that $u_{i_{1}}<v_{i_{1}}$ and $u_{i_{2}}>v_{i_{2}}$. Let $\left(u_{i}^{\prime}\right),\left(v_{i}^{\prime \prime}\right)$ be the monotone representatives of $\left(u_{i}\right),\left(v_{i}\right)$ respectively. If $i_{1}^{\prime}<i_{2}^{\prime}$ then $v_{i_{1}}^{\prime \prime}>u_{i_{1}}^{\prime} \geqq u_{i_{2}}^{\prime}>v_{1_{2}}^{\prime \prime}$ so that $v_{i_{1}}^{\prime \prime} \geqq v_{i_{2}}^{\prime \prime}+2$. Let $\left(t_{i}^{\prime \prime}\right)$ be the $k$-tuple equal to $\left(v_{i}^{\prime \prime}\right)$ for $i \neq i_{1}^{\prime \prime}$, $i_{2}^{\prime \prime}, t_{i_{1}}^{\prime \prime}=v_{i_{1}}^{\prime \prime}-1$ and $t_{i_{2}}^{\prime \prime}=v_{i_{2}}^{\prime \prime}+1$. Then $\left(t_{i}^{\prime \prime}\right)$ is majorized by $\left(r_{i}\right)$. If $\left(t_{i}\right)$ is obtained by reversing the permutation $\left(v_{i}\right) \rightarrow\left(v_{i}^{\prime \prime}\right)$ and applying it to $\left(t_{i}^{\prime \prime}\right)$ then $\left(t_{i}\right)$ is also majorized by $\left(r_{i}\right)$. So

$$
\max \left(u_{i}, t_{i}\right)= \begin{cases}\max \left(u_{i}, v_{i}\right), & i \neq i_{1} \\ v_{i_{1}}-1, & i=i_{1}\end{cases}
$$

and $d\left(\left(u_{i}\right),\left(t_{i}\right)\right)<d\left(\left(u_{i}\right),\left(v_{i}\right)\right)$. By induction on $d$, there exist $\left(\bar{u}_{i}\right),\left(\bar{v}_{i}\right)$ such that $d\left(\left(\bar{u}_{i}\right),\left(\bar{v}_{i}\right)\right)=\left|r_{1}^{*}-s_{1}^{*}\right|$ and $\max \left(\bar{u}_{i}, \bar{v}_{i}\right) \leqq \max \left(u_{i}, t_{i}\right) \leqq$ $\max \left(u_{i}, v_{i}\right)$ for $i=1, \cdots, k$. The proof is complete if $i_{1}^{\prime}<i_{2}^{\prime}$.

Otherwise $i_{1}^{\prime}>i_{2}^{\prime}$ which implies that $i_{1}^{\prime \prime}<i_{2}^{\prime \prime}$. The proof is similar if the latter holds.

Now suppose that $\left(e_{i}\right)$ and $\left(f_{i}\right)$ are $k$-tuples, then $\Pi a_{i}^{e_{i}}$ and $\Pi a_{i}^{f_{i}}$ are elements of $P\left(a_{i}\right)$. The next theorem characterizes the elements in the base for their meet in terms of the exponents of the $A_{i}$ 's.

THEOREM 4.2. If $\Pi a_{i}^{e_{i}}$ and $\Pi a_{i}^{f_{i}}$ are elements of $P\left(a_{i}\right)$ with $f_{1}^{* *} \geqq e_{1}^{* *}$ then $\Pi a_{i}^{e_{i}} \wedge \Pi a_{i}^{f_{i}}=\left\{\Pi A_{i}^{v_{i}} \mid\left(v_{i}\right) \prec\left(f_{i}^{*}\right)\right.$ and $\left(v_{i}\right) \geqq_{p}\left(u_{i}\right)$ for some $\left.\left(u_{i}\right) \prec\left(e_{i}^{*}\right)\right\}$.

Proof. Since $R L\left(A_{i}\right)$ is distributive, the meet described in the 
theorem is the join of all products of the $A_{i}$ whose exponent $k$-tuples are $\left(\max \left(u_{i}, v_{i}\right)\right)$ for $\left(u_{i}\right) \prec\left(e_{i}^{*}\right)$ and $\left(v_{i}\right) \prec\left(f_{i}^{*}\right)$. If $d\left(\left(u_{i}\right),\left(v_{i}\right)\right)$ is greater than $f_{1}^{* *}-e_{1}^{* *}$, then $\left(\max \left(u_{i}, v_{i}\right)\right) \geqq_{p}\left(\max \left(\bar{u}_{i}, \bar{v}_{i}\right)\right)$ for some $\left(\bar{u}_{i}\right)$ and $\left(\bar{v}_{i}\right)$ majorized by $\left(e_{i}^{*}\right)$ and $\left(f_{i}^{*}\right)$ respectively. Hence the product of the $A_{i}$ 's with exponent $k$-tuple $\left(\max \left(u_{i}, v_{i}\right)\right)$ can be left out of the minimal base for the meet. But $d\left(\left(u_{i}\right),\left(v_{i}\right)\right)>f_{1}^{* *}-e_{1}^{* *}$ if and only if $\left(v_{i}\right) \nsupseteq_{p}\left(u_{i}\right)$. Hence the elements left in the minimal base for the meet have the form desired.

To show that the meet of two products of the $a_{i}$ 's is again such a product, we need

Lemma 4.3. Let $\left(e_{i}^{*}\right)$ and $\left(f_{i}^{*}\right)$ be monotone k-tuples and $t_{i}^{*}=$ $\max \left(e_{i}^{* *}, f_{i}^{* *}\right)-\max \left(e_{i+1}^{* *}, f_{i+1}^{* *}\right)$ for $i=1, \cdots, k$ where we agree that $e_{k+1}^{*}=f_{k+1}^{*}=0$. Then $\left(t_{i}^{*}\right)$ is also monotone.

Proof.

$$
\begin{aligned}
\max & \left(e_{i}^{* *}, f_{i}^{* *}\right)+\max \left(e_{i+2}^{* *}, f_{i+2}^{* *}\right) \\
& \geqq \max \left(e_{i}^{* *}+e_{i+2}^{* *}, f_{i}^{* *}+f_{i+2}^{* *}\right) \\
& \geqq \max \left(2 e_{i+1}^{* *}, 2 f_{i+1}^{* *}\right) \\
& =2 \max \left(e_{i+1}^{* *}, f_{i+1}^{* *}\right) .
\end{aligned}
$$

So that $t_{i}^{*} \geqq t_{i+1}^{*}$ for $i=1, \cdots, k-1$.

THEOREM 4.4. Let $\left(e_{i}\right)$ and $\left(f_{i}\right)$ be $k$-tuples, then the meet of $\Pi a_{i}^{e_{i}}$ and $\Pi a_{i}^{f_{i}}$ is the product $\Pi a_{i}^{t_{i}}$ where $t_{i}^{*}$ is given in Lemma 4.3.

Proof. We may assume that $e_{1}^{* *} \geqq f_{1}^{* *}$. From above it suffices to show that the set $\mathfrak{B}=\left\{\left(u_{i}\right) \mid\left(u_{i}\right) \prec\left(e_{i}^{*}\right)\right.$ and $\left(u_{i}\right) \geqq_{p}\left(v_{i}\right)$ for some $\left.\left(v_{i}\right) \prec\left(f_{i}^{*}\right)\right\}$ is equal to the set $\mathbb{E}=\left\{\left(u_{i}\right) \mid\left(u_{i}\right) \prec\left(t_{i}^{*}\right)\right\}$.

$\mathfrak{B} \subseteq \mathfrak{E}$. If $\left(u_{i}\right)$ is in $\mathfrak{B}$ then $\left(u_{i}\right) \prec\left(e_{i}^{*}\right)$ and $\left(u_{i}\right) \geqq_{p}\left(v_{i}\right)$ for $\left(v_{i}\right) \prec\left(f_{i}^{*}\right)$. Then $d\left(\left(u_{i}\right),\left(v_{i}\right)\right)=e_{1}^{* *}-f_{1}^{* *}$ so that $w_{1}^{*}=e_{1}^{* *}$ where $w_{i}=\max \left(u_{i}, v_{i}\right)$ for $i=1, \cdots, k$. Moreover, for $j=2, \cdots, k, u_{j}^{*} \geqq$ $v_{j}^{*} \geqq f_{j}^{* *}$ since if $v_{j}^{*}<f_{j}^{* *}$, then $\sum_{1}^{j-1} v_{i}^{\prime} \geqq \sum_{1}^{j-1} v_{i}>\sum_{1}^{j-1} f_{i}^{*}$ where $\left(v_{i}^{\prime}\right)$ is the monotone representative of $\left(v_{i}\right)$ which contradicts $\left(v_{i}\right) \prec$ $\left(f_{i}^{*}\right)$. Therefore $\sum_{1}^{j-1} u_{i}=e_{1}^{* *}-u_{j}^{*} \leqq e_{1}^{* *}-f_{1}^{* *}$. But

$$
\begin{aligned}
\sum_{l=1}^{j-1} t_{l}^{*} & =\sum_{l=1}^{j-1}\left[\max \left(e_{l}^{* *}, f_{l}^{* *}\right)-\max \left(e_{l+1}^{* *}, f_{l+1}^{* *}\right)\right] \\
& =\max \left(e_{1}^{* *}, f_{1}^{* *}\right)-\max \left(e_{j}^{* *}, f_{j}^{* *}\right) \\
& =\sum_{1}^{j-1} e_{i}^{*}-\left\{\begin{array}{l}
0 \text { if } e_{j}^{* *} \geqq f_{j}^{* *} \\
f_{j}^{* *}-e_{j}^{* *} \text { if } f_{j}^{* *}>e_{j}^{* *}
\end{array}\right. \\
& =\left\{\begin{array}{l}
\sum_{1}^{j-1} e_{i}^{*} \text { if } e_{j}^{*} \geqq f_{j}^{*} \\
e_{1}^{* *}-f_{j}^{* *} \text { if } f_{j}^{* *}>e_{j}^{* *} .
\end{array}\right.
\end{aligned}
$$


Hence $\sum_{1}^{j-1} u_{i} \leqq \sum_{1}^{j-1} t_{i}^{*}$ and $\left(u_{i}\right) \prec\left(t_{i}^{*}\right)$, i.e., $\left(u_{i}\right)$ is in $\sqrt{5}$.

(5) $\subseteq \mathfrak{B}$. Let $\left(u_{i}\right)$ be a $k$-tuple majorized by $\left(t_{i}^{*}\right)$. By symmetry, we may assume that $\left(u_{i}\right)$ is monotone. Since, $\left(t_{i}^{*}\right) \prec\left(e_{i}^{*}\right)$, we have $\left(u_{i}\right) \prec\left(e_{i}^{*}\right)$. For $i=1, \cdots, k$ let $v_{i}=\min \left(u_{i}, f_{1}^{*}+\cdots+f_{i}^{*}-\sum_{1}^{i-1} v_{j}\right)$ setting $v_{0}=0$. We claim

（\#) $\sum_{1}^{q} v_{i}=\min _{p}\left\{\sum_{0}^{p} f_{i}^{*}+\sum_{p+1}^{q} u_{i}\right\}$ where the minimum is taken for $p$ ranging from 0 to $q$ and $f_{0}=0=\sum_{s}^{r} u_{i}$ whenever $r<s$.

(\#) is clear if $q=1$. For $q>1$,

$$
\begin{aligned}
\sum_{1}^{q} v_{i} & =\sum_{1}^{q-1} v_{i}+\min \left(u_{q}, f_{1}^{*}+\cdots+f_{q}^{*}-\sum_{1}^{q-1} v_{i}\right) \\
& =\min \left(u_{q}+\sum_{1}^{q-1} v_{i}, \sum_{1}^{q} f_{i}^{*}\right) \\
& =\min \left(u_{q}+\min _{p=0, \cdots, q-1}\left\{\sum_{0}^{q} f_{i}^{*}+\sum_{p+1}^{q} u_{i}\right\}, \sum_{1}^{q} f_{i}^{*}\right) \\
& =\min _{p=0, \cdots, q}\left\{\sum_{0}^{p} f_{i}^{*}+\sum_{p+1}^{q} u_{i}\right\}
\end{aligned}
$$

where the third equality follows by induction. Therefore (\#) holds. Moreover, $\left(v_{i}\right)$ is monotone: If $q$ is any integer, $1 \leqq q<k-1$, then

(1) $2\left(\sum_{1}^{q} u_{i}\right) \geqq 2\left(\sum_{1}^{q-1} u_{i}\right)+u_{q}+u_{q+1}$

(2) $2\left(\sum_{1}^{p} f_{i}^{*}+\sum_{p+1}^{q} u_{i}\right) \geqq 2\left(\sum_{1}^{p} f_{i}^{*}+\sum_{p+1}^{q-1} u_{i}\right)+u_{q}+u_{q+1}$

(3) $2\left(\sum_{1}^{q} f_{i}^{*}\right) \geqq 2\left(\sum_{1}^{q-1} f_{i}^{*}\right)+f_{q}^{*}+f_{q+1}^{*}$

since $\left(u_{i}\right)$ and $\left(f_{i}^{*}\right)$ are monotone. Hence each integer on the left of the inequalities of (1), (2), or (3) is greater than or equal to

$$
\begin{aligned}
\min [ & 2\left(\sum_{1}^{q-1} u_{i}\right)+u_{q}+u_{q+1}, 2\left(f_{1}^{*}+u_{2}+\cdots+u_{q-1}\right) \\
& +u_{q}+u_{q+1}, \cdots, 2\left(f_{1}^{*}+\cdots+f_{q-1}^{*}\right) \\
& \left.+f_{q}^{*}+u_{q+1}, 2\left(\sum_{1}^{q} f_{i}^{*}\right)+f_{q}^{*}+f_{q+1}^{*}\right] \\
& \geqq \sum_{1}^{q+1} v_{i}+\sum_{1}^{q-1} v_{i} .
\end{aligned}
$$

So from (\#), $\sum_{1}^{q} v_{i} \geqq 1 / 2\left[\sum_{1}^{q+1} v_{i}+\sum_{1}^{q-1} v_{i}\right]$ and $v_{q}=\sum_{1}^{q} v_{i}-\sum_{1}^{q-1} v_{i} \geqq$ $\sum_{1}^{q+1} v_{i}-\sum_{1}^{q} v_{i}=v_{q+1}$ for $q=1, \cdots, k-1$. Hence $\left(v_{i}\right)$ is monotone.

Finally, again from (\#) $v_{1}^{*}=\min _{j=1, \ldots, k}\left\{\sum_{1}^{j-1} f_{i}^{*}+u_{j}^{*}\right\}$ and since $u_{j}^{*} \geqq t_{j}^{* *}=\max \left(e_{j}^{* *}, f_{j}^{* *}\right) \geqq f_{j}^{* *}$ for $j=1, \cdots, k$, we have $f_{1}^{*}+\cdots+$ $f_{j-1}^{*}+u_{j}^{*} \geqq f_{1}^{* *}$ for each $j$. Hence $v_{1}^{*}=f_{1}^{* *}$. Therefore $\left(v_{i}\right) \prec\left(f_{i}^{*}\right)$ since by definition of the $v_{i}$ 's, $v_{1}+\cdots+v_{j} \leqq f_{1}^{*}+\cdots+f_{j}^{*}$ for each $j$. Since $\left(v_{i}\right)_{p} \leqq\left(u_{i}\right)$ and $\left(u_{i}\right) \prec\left(e_{i}^{*}\right)$, we have $\left(u_{i}\right)$ is in $\mathfrak{B}$.

It follows from the property in $R L\left(A_{i}\right)$ that multiplication in $P\left(a_{i}\right)$ distributes over joins. Consequently 
THEOREM 4.5. The set of all finite joins of products of the elementary symmetric elements in $A_{1}, \cdots, A_{k}$ is a (distributive) multiplicative sublattice of $R L\left(A_{i}\right)$ and is the sublattice generated by $a_{1}, \cdots, a_{k}$.

In the next two sections we investigate the structure of the lattice $P\left(a_{i}\right)$. In $\S 5$ we show that the factorization of products of the $a_{i}$ is unique and in $\S 6$ we investigate the principal elements and the residual division in $P\left(a_{i}\right)$.

5. Unique factorization of products of elementary symmetric elements. If $\Pi a_{i}^{e_{i}}$ and $\Pi a_{i}^{f_{i}}$ are products in $P\left(a_{i}\right)$ and $\Pi a_{i}^{e_{i}} \leqq \Pi a_{i}^{f_{i}}$, then every element in the minimal base for $\Pi a_{i}^{e_{i}}$ must be less than or equal to one of the elements in the minimal base for $\Pi a_{i}^{f_{i}}$. That is, whenever $\left(r_{i}\right) \prec\left(e_{i}^{*}\right)$ then $\left(r_{i}\right) \geqq_{p}\left(s_{i}\right)$ for some $\left(s_{i}\right) \prec\left(f_{i}^{*}\right)$. When this occurs we say that $\left(e_{i}^{*}\right)$ is dominated by $\left(f_{i}^{*}\right)$ and write $\left(e_{i}^{*}\right)$ $\operatorname{dom}\left(f_{i}^{*}\right)$. Hence, $\Pi \alpha_{\imath}^{e_{i}} \leqq \Pi a_{i}^{f_{i}}$ if and only if $\left(e_{i}^{*}\right) \operatorname{dom}\left(f_{i}^{*}\right)$. Hence,

Lemma 5.1. Dom is a partial order on the set of monotone $k$-tuples.

Lemma 5.1 and the definition of dom establish the next theorem.

THEOREM 5.2. The set of products of the $a_{i}$ 's is order isomorphic to the poset of monotone k-tuples ordered by dom via the map $\Pi a_{i}^{e_{i}} \mapsto\left(e_{i}^{*}\right)$. In particular, since this mapping is well defined, factorization of a product of elementary symmetric elements is unique.

Using the order dom, we show that in $P\left(a_{i}\right)$ any product of the elementary symmetric elements is join irreducible.

THEOREM 5.3. Products of the elementary symmetric elements in $P\left(a_{i}\right)$ are join irreducible.

Proof. Suppose that $\Pi a_{i}^{g_{i}}=\Pi a_{i}^{e_{i}} \vee \cdots \vee \Pi a_{i}^{f_{i}}$. Since minimal bases in $R L\left(A_{i}\right)$ are unique, the element $\Pi A_{i}^{g_{i} *}$ which is in the minimal base for $\Pi a_{i}^{g_{i}}$ must appear in the minimal base for one of the products of the $a_{i}$ 's on the right, say $\Pi a_{i}^{e_{i}}$. Then $\left(g_{i}^{*}\right) \prec\left(e_{i}^{*}\right)$. But since $\Pi a_{i}^{e_{i}} \leqq \Pi a_{i}^{g_{i}},\left(e_{i}^{*}\right) \operatorname{dom}\left(g_{i}^{*}\right)$. So $\left(e_{i}^{*}\right) \geqq_{p}\left(v_{i}\right)$ where $\left(v_{i}\right) \prec\left(g_{i}^{*}\right)$. Therefore $\left(e_{i}^{*}\right)=\left(v_{i}\right)$ and $\left(e_{i}^{*}\right) \prec\left(g_{i}^{*}\right)$. Consequently $\left(e_{i}^{*}\right)=\left(g_{i}^{*}\right)$; and $\Pi \alpha_{i}^{g_{i}}$ is join irreducible.

CoROllaRy 5.4. Elements in $P\left(a_{i}\right)$ have unique minimal bases as joins of products of the $a_{i}$ 's. 


\section{Proof. [2, p. 183].}

6. Residuation and join principal elements in $P\left(a_{i}\right)$. In Lemma 4.1 we used the technique of subtracting one from a position in a $k$-tuple and adding one further to the right in such a way that monotonicity of the $k$-tuple was maintained. We call this process a monotone $(-1,1)$-change and remark that these changes characterize majorization [cf. 4].

Proposition 6.1. Let $\left(r_{i}\right)$ and $\left(s_{i}\right)$ be manotone $k$-tuples such that $\left(r_{i}\right) \prec\left(s_{i}\right)$ and $\left(\bar{r}_{i}\right)$ be obtained from $\left(r_{i}\right)$ by a monotone $(-1,1)$ change. Then $\left(\bar{r}_{i}\right) \prec\left(s_{i}\right)$.

Proposition 6.2. Every mototone k-tuple majorized by a monotone $k$-tuple $\left(s_{i}\right)$ can be obtained from $\left(s_{i}\right)$ by a sequence of monotone $(-1,1)$-changes.

Proof. Let $\left(r_{i}\right)$ be a monotone $k$-tuple such that $\left(\boldsymbol{r}_{i}\right) \prec\left(s_{i}\right)$. We show that $\left(r_{i}\right)$ can be obtained by a sequence of $(-1,1)$-changes by induction on $d\left(\left(r_{i}\right),\left(s_{i}\right)\right)=\sum_{1}^{k}\left|r_{i}-s_{i}\right|=t$. If $t=0,\left(r_{i}\right)=\left(s_{i}\right)$. For $t>0$, let $\mathfrak{D}=\left\{i: s_{i}>r_{i}\right\}$. If $\mathfrak{D}$ is empty, then $\left(s_{i}\right)_{p} \leqq\left(r_{i}\right)$ and $\left(r_{i}\right)=$ $\left(s_{i}\right)$ since $r_{1}^{*}=s_{1}^{*}$. Hence $\left(\mathcal{D}\right.$ is nonempty. Set $i_{0}=\max \mathfrak{D}$. Moreover, $i_{0}<k$ since $i_{0}=k$ implies $\sum_{1}^{k-1} r_{i}>\sum_{1}^{k-1} s_{i}$ contradicting $\left(r_{i}\right) \prec$

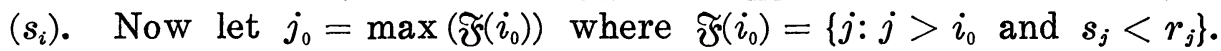
If $\mathfrak{F}\left(i_{0}\right)$ is empty and $i_{0}=1$, then $j>1$ implies $s_{j} \geqq r_{j}$ so that $s_{j}=r_{j}$ for $j>1$. But then $s_{1}=r_{1}$, a contradiction. If $\mathfrak{F}\left(i_{0}\right)$ is empty and $i_{0}>1$, then

$$
\sum_{1}^{i_{0}} s_{j}+r_{i_{0}+1}^{*} \geqq \sum_{1}^{i_{0}} r_{j}+r_{i_{0}+1}^{*}=s_{1}^{*} \geqq \sum_{1}^{i_{0}} s_{j}+r_{i_{0}+1}^{*}
$$

and $s_{i_{0}+1}^{*}=r_{i_{0}+1}^{*}$. But then $s_{q}=r_{q}$ for $i_{0}+1 \leqq q \leqq k$. Therefore $\sum_{1}^{i_{0}} r_{j}=\sum_{1}^{i_{0}} s_{j}$ with $s_{i_{0}}>r_{i_{0}}$. This implies $\sum_{1}^{i_{0}-1} r_{j}>\sum_{1}^{i_{0}-1} s_{j}$. Again this is a contradiction. Hence $\mathfrak{F}\left(i_{0}\right)$ is nonempty.

Let $\left(\bar{s}_{i}\right)$ be obtained from $\left(s_{i}\right)$ by a monotone $(-1,1)$-change at the $i_{0}, j_{0}$ places. Then $\left(\bar{s}_{i}\right)$ is monotone and we claim that $\left(r_{i}\right) \prec\left(\bar{s}_{i}\right)$. Since $\left(r_{i}\right) \prec\left(s_{i}\right)$ and $\bar{s}_{i_{0}}=s_{i_{0}}-1 \geqq r_{i_{0}}$ the desired inequality holds for $1 \leqq q \leqq i_{0}$. If $i_{0}<q<j_{0}$ and $\sum_{1}^{q} r_{i}>\sum_{1}^{q} \bar{s}_{i}$, then $\sum_{1}^{q} r_{i}=\sum_{1}^{q} s_{i}$. There is some $p>q$ such that $\sum_{1}^{p} r_{i}<\sum_{1}^{p} s_{i}$. Let $p_{0}$ be the least such $p$. Then $\left(r_{q+1}, \cdots, r_{p_{0}-1}\right)=\left(s_{q+1}, \cdots, s_{p_{0}-1}\right)$ and $r_{p}<s_{p}$. This contradicts the choice of $i_{n}$ if $p_{0}>q+1$. If $p_{0}=q+1$, then $r_{q+1}<s_{q+1}$ again gives a contradiction to the choice of $i_{0}$. Hence for $1 \leqq q<j_{0}$, the sum of the first $q r_{i}$ 's is less than or equal to the sum of the first $\bar{s}_{i}$ 's. The inequalities are clear if $j_{0} \leqq q \leqq k$ so 
that $\left(r_{i}\right) \prec\left(\bar{s}_{i}\right)$. Since $d\left(\left(r_{i}\right),\left(\bar{s}_{i}\right)\right)<d\left(\left(r_{i}\right),\left(s_{i}\right)\right)$, the theorem follows by induction.

Note that if $\left(r_{i}\right)$ can be obtained from $\left(s_{i}\right)$ by a sequence of monotone $(-1,1)$-changes, then we can obtain $\left(s_{i}\right)$ from $\left(r_{i}\right)$ by a sequence of $(1,-1)$-changes.

Proposition 6.4. If $\left(r_{i}\right)$ is a monotone k-tuple, then each monotone $k$-tuple which majorizes $\left(r_{i}\right)$ can be obtained from $\left(r_{i}\right)$ by a finite sequence of monotone $(1,-1)$-changes.

Our next objective is to show that $P\left(a_{i}\right)$ is closed under residuation. Since $P\left(a_{i}\right)$ is distributive and a product of the $a_{i}$ 's is join irreducible, the following lemma tells us that to check closure of residuation in $P\left(a_{i}\right)$ we only need check the residuation of a product of the $a_{i}$ 's by another such product.

LEMMA 6.5. If every element in a distributive multiplicative lattice $L$ is a join of join irreducibles and join irreducibles are closed under multiplication, then for $Z$ join irreducible and $X, Y$ in $L$,

$$
(X \vee Y: Z)=(X: Z) \vee(Y: Z)
$$

Proof. If $W$ is join irreducible such that $W Z \leqq X \vee Y$, then $W Z=(W Z \wedge X) \vee(W Z \wedge Y)$. Hence $W Z \leqq X$ or $W Z \leqq Y$ and $W \leqq(X: Z) \vee(Y: Z)$. Therefore $(X \vee Y: Z) \leqq(X: Z) \vee(Y: Z)$. Since the opposite inequality holds, the lemma is proved.

COROLLARY 6.6. $P\left(a_{i}\right)$ is closed under residuation if and only if $(X: Y)$ is in $P\left(a_{i}\right)$ for any join irreducibles $X, Y$ in $P\left(a_{i}\right)$.

Proof. If $X_{1}, \cdots, X_{m}, Y_{1}, \cdots, Y_{n}$ are products of the $a_{i}$ 's in $P\left(a_{i}\right)$, then

$$
\left(X_{1} \vee \cdots \vee X_{m}: Y_{1} \vee \cdots \vee Y_{n}\right)=\bigwedge_{j=1}^{n}\left(\bigvee_{i=1}^{m}\left(X_{i}: Y_{j}\right)\right)
$$

by Lemma 6.5 .

Technical Lemmas 6.7 and 6.8 allow us to prove $P\left(a_{i}\right)$ is closed under residuation.

LEMMA 6.7. If $\left(q_{i}\right) \prec\left(g_{i}\right)$ and $\left(g_{i}\right) \geqq_{p}\left(b_{i}\right)$ for some $\left(b_{i}\right) \prec\left(e_{i}^{*}\right)$, then $\left(q_{i}\right) \geqq_{p}\left(a_{i}\right)$ for some $\left(a_{i}\right) \prec\left(e_{i}^{*}\right)$.

Proof. First we assume $\left(q_{i}\right)$ is monotone and we may assume 
that $\left(b_{i}\right)$ is monotone. Let $\left(\bar{q}_{i}\right)$ be obtained from $\left(q_{i}\right)$ by a monotone $(-1,1)$-change at the $l, m$ places where $l<m$. If $\left(\bar{q}_{i}\right) \geqq_{p}\left(b_{i}\right)$, let $\left(a_{i}\right)=\left(b_{i}\right)$. If not, then $\bar{q}_{i} \geqq b_{i}$ for $i \neq l$ implies that $\bar{q}_{l}<b_{l}$. Since $q_{l} \geqq b_{l}$, we have $q_{l}=b_{l}$ and $b_{l+1}<b_{l}$. (If $b_{l+1}=b_{l}$ then $b_{l}=b_{l+1} \leqq$ $q_{l+1}<q_{l}=b_{l}$, a contradiction.) Let $\bar{b}_{l}=b_{l}-1$ and $\bar{b}_{i}=b_{i}$ for $i \neq l$. If $\bar{b}_{m-j}<\bar{b}_{m-(j+1)}$ and $q_{m-j}>\bar{b}_{m-j}$ for some $0 \leqq j \leqq m-l+1$ then $\left(a_{i}\right)$ defined by

$$
a_{i}= \begin{cases}\bar{b}_{i} & \text { for } i \neq m-j \\ \bar{b}_{i}+1 & \text { for } i+m-j\end{cases}
$$

satisfies the conclusion of the lemma. Otherwise $\bar{b}_{m-1}=\bar{b}_{m}$ so that $q_{m-1} \geqq \bar{q}_{m}>\bar{b}_{m}=\bar{b}_{m-1}$. Then we can construct $\left(a_{i}\right)$ as desired unless $\bar{b}_{m-1}=\bar{b}_{m-2}$ in which case $q_{m-2} \geqq \bar{q}_{m-1}>\bar{b}_{m-1}=\bar{b}_{m-2}$. Again we can construct the desired $\left(a_{i}\right)$ unless $\bar{b}_{m-2}=\bar{b}_{m-3}$. Continuing, we conclude all of the $\bar{b}_{i}$ 's for $i$ from $l$ to $m$ are equal if $\left(a_{i}\right)$ cannot be constructed. But we know that $\bar{b}_{m}<\bar{q}_{m}=q_{m}+1 \leqq \bar{q}_{l}-q_{l}-1=b_{l}-1=\bar{b}_{l}$; that is, $\bar{b}_{m}<\bar{b}_{l}$, a contradiction. Hence $\left(a_{i}\right)$ exists such that $\left(a_{i}\right) \prec$ $\left(e_{i}^{*}\right)$ and $\left(\bar{q}_{i}\right) \geqq_{p}\left(a_{i}\right)$. Since any monotone $k$-tuple majorized by $\left(g_{i}\right)$ can be obtained by a finite sequence of monotone $(-1,1)$-changes, the lemma is proved for $\left(q_{i}\right)$ monotone.

If $\left(q_{i}\right)$ is not monotone, let $\left(q_{i}^{\prime}\right)$ be its monotone representative. Then for some $\left(a_{i}^{\prime}\right) \prec\left(e_{i}^{*}\right),\left(q_{i}^{\prime}\right) \geqq_{p}\left(a_{i}^{\prime}\right)$. But then $\left(q_{i}\right) \geqq_{p}\left(a_{i}\right)$ and $\left(a_{i}\right) \prec\left(e_{i}^{*}\right)$.

Lemma 6.8. Let $\left(u_{i}\right),\left(f_{i}^{*}\right),\left(b_{i}\right)$, and $\left(e_{i}^{*}\right)$ be monotone $k$-tuples with $\left(u_{i}\right)+\left(f_{i}^{*}\right) \geqq_{p}\left(b_{i}\right)$ for some $\left(b_{i}\right) \prec\left(e_{i}^{*}\right)$ and suppose $\left(q_{i}\right) \prec\left(f_{i}^{*}\right)$, then $\left(u_{i}\right)+\left(q_{i}\right) \geqq_{p}\left(c_{i}\right)$ for some $\left(c_{i}\right) \prec\left(e_{i}^{*}\right)$.

Proof. Since $\left(q_{i}\right) \prec\left(f_{i}^{*}\right),\left(u_{i}+q_{i}\right) \prec\left(u_{i}+f_{i}^{*}\right)$. Moreover, since $\left(u_{i}\right)+\left(f_{i}^{*}\right)=\left(u_{i}+f_{i}^{*}\right) \geqq_{p}\left(b_{i}\right)$ for some $\left(b_{i}\right) \prec\left(e_{i}^{*}\right)$, by Lemma 6.7 $\left(u_{i}+q_{i}\right)=\left(u_{i}\right)+\left(q_{i}\right) \geqq_{p}\left(c_{i}\right)$ for some $\left(c_{i}\right) \prec\left(e_{i}^{*}\right)$.

CoROLlARY 6.9. If $\left(u_{i}\right)$ is a monotone k-tuple then $\Pi A_{i}^{u_{i}} \leqq$ $\Pi \alpha_{i}^{e_{i}}: \Pi \alpha_{i}^{f_{i}}$ if and only if $\left(u_{i}+f_{i}^{*}\right) \geqq_{p}\left(b_{i}\right)$ for some $\left(b_{i}\right) \prec\left(e_{i}^{*}\right)$.

Proof. If $\left(\bar{q}_{i}\right)$ is the monotone representative for $\left(q_{i}\right)$ and $\left(\overline{u_{i}+q_{i}}\right)$ is the monotone representative for $\left(u_{i}+q_{i}\right)$ for some $\left(q_{i}\right) \prec\left(f_{i}^{*}\right)$, then

$$
\sum \overline{u_{i}+q_{i}} \leqq \sum u_{i}+\sum \bar{q}_{i} \leqq \sum u_{i}+\sum f_{i}^{*}=\sum\left(u_{i}+f_{i}^{*}\right)
$$

where the indices run from 1 to $j$ for $1 \leqq j \leqq k-1$ and $\left(u_{1}+q_{1}\right)^{*}=$ $u_{1}^{*}+q_{1}^{*}=u_{1}^{*}+f_{1}^{* *}=\left(u_{1}+f_{1}^{*}\right)^{*}$. Hence the condition is sufficient.

Necessity is clear.

Note that a symmetric element $E$ in $R L\left(A_{i}\right)$ is the join of pro- 
ducts of the $a_{i}$ 's if and only if whenever $\Pi A_{i}^{r_{i}} \leqq E$ with $\left(r_{i}\right)$ monotone and $\left(s_{i}\right)$ is obtained from $\left(r_{i}\right)$ by a sequence monotone $(-1,1)$ changes, then $\Pi A_{i}^{s_{i}} \leqq E$; for then $E=\mathrm{V}\left\{\Pi a_{i}^{t_{i}-t_{i+1}}:\left(t_{i}\right)\right.$ is monotome and $\Pi A_{i}^{t_{i}}$ is in the minimal base for $\left.E\right\}$. As before we set $t_{k+1}=0$.

\section{THEOREM 6.10. $P\left(a_{i}\right)$ is closed under residuation.}

Proof. Suppose that $\left(u_{i}\right)$ is monotone and that $\Pi A_{i}^{u_{i}} \leqq\left(\Pi a_{i}^{e_{i}}: \Pi a_{i}^{f_{i}}\right)$. Let $\left(v_{i}\right)$ be obtained from $\left(u_{i}\right)$ by a monotone $(-1,1)$-change. Then $\Pi a_{i}^{u_{i}} \cdot \Pi A_{i}^{f^{*}} \leqq \Pi a_{i}^{e_{i}}$ so that $\left(u_{i}\right)+\left(f_{i}^{*}\right) \geqq{ }_{p}\left(b_{i}\right)$ for some $\left(b_{i}\right) \prec\left(e_{i}^{*}\right)$. So by Lemma $6.8\left(v_{i}\right)+\left(f_{i}^{*}\right) \geqq_{p}\left(c_{i}\right)$ for some $\left(c_{i}\right) \prec\left(e_{i}^{*}\right)$ since $\left(v_{i}\right)+\left(f_{i}^{*}\right)$ is obtained from $\left(u_{2}\right)+\left(f_{i}^{*}\right)$ by a monotone $(-1,1)$-change. Hence $\Pi A_{i}^{v_{i}} \leqq\left(\Pi \alpha_{i}^{e_{i}}: \Pi a_{i}^{f_{i}}\right)$ by Corollary 6.9. Therefore $\Pi a_{i}^{u_{i}-u_{i+1}} \leqq\left(\Pi a_{i}^{e_{i}}: \Pi a_{i}^{f_{i}}\right)$ so the residual is the join of all such products $\Pi a_{i}^{u_{i}-u_{i+1}}$ where $\left(u_{i}\right)$ is monotone and $\Pi A_{i}^{u_{i}} \cdot \Pi a_{i}^{f_{i}} \leqq a_{i}^{e_{i}}$. (We set $u_{k+1}=0$.) Since this is an element in $P\left(a_{2}\right)$ our proof is complete.

Proposition 6.11. Each product of the elementary symmetric elements is a weak join principal element in $P\left(a_{i}\right)$.

Proof. Let $k>1$. It suffices to show that $\left(\Pi a_{i}^{e_{i}}: a_{t}\right)=\Pi_{i \neq t} a_{i}^{e_{i}} \cdot a_{t}^{e^{t}} t^{-1}$ whenever $e_{t} \geqq 1$. And since the product on the right is clearly less than or equal to the residual, we only need demonstrate the opposite inequality. So suppose that $\Pi A_{i}^{t_{i}} \leqq\left(a_{i}^{e_{i}}: a_{t}\right)$ where $e_{t} \geqq 1$. By symmetry we assume $\left(t_{i}\right)$ is monotone. Let $\left(f_{i}^{*}\right)=(1,1, \cdots, 1,0, \cdots, 0)$ with 1's in the first $t$ positions. Then

$$
\left(t_{i}\right)+\left(f_{i}^{*}\right) \geqq_{p}\left(b_{i}\right) \text { for some }\left(b_{i}\right) \prec\left(e_{i}^{*}\right) \text {. }
$$

Let $\left(u_{i}\right)$ be the lexicographic maximum of the $p$-minimal $k$-tuples which are ${ }_{p} \leqq\left(t_{i}\right)$ and satisfy $(\nabla)$ with $\left(u_{i}\right)$ in place of $\left(t_{i}\right)$. Note that $\left(u_{i}\right)$ is monotone since if $\left(\bar{u}_{i}\right)$ is the monotone representative of $\left(u_{i}\right)$ then $\left(\bar{u}_{i}\right)_{p} \leqq\left(t_{i}\right)$ and by symmetry $\Pi A_{i}^{\bar{u}_{i}} \leqq\left(\Pi a_{i}^{e_{i}}: a_{t}\right)$. But $\left(\bar{u}_{i}\right) \geqq_{l}\left(u_{i}\right)$ and since $\left(\bar{u}_{i}\right)$ is $p$-minimal $\left(u_{i}\right)=\left(\bar{u}_{i}\right)$. Moreover, $\left(u_{i}\right)+$ $\left(f_{i}^{*}\right)=\left(u_{i}+f_{i}^{*}\right)$ is monotone so we can choose $\left(b_{i}\right)$ monotone and $l$-maximum satisfying $(\nabla)$ with $\left(t_{i}\right)$ replaced by $\left(u_{i}\right)$.

Claim. $\left(u_{i}\right) \prec\left(\left(e_{i}-f_{i}\right)^{*}\right)$. For then $\Pi A_{i}^{t_{i}} \leqq \Pi A_{i}^{u_{i}} \leqq \Pi_{i \neq t} a_{i}^{e_{i}} \cdot a_{t}^{e_{t}-1}$.

First suppose that $\sum_{1}^{r} b_{i}=\sum_{1}^{r} e_{i}^{*}$ for some $r<k$. Set $\left(g_{1}, \cdots, g_{r}\right)=$ $\left(f_{1}, \cdots, f_{r-1}, f_{r}^{*}\right)$ and $\left(h_{1}, \cdots, h_{r}\right)=\left(e_{1}, \cdots, e_{r-1}, e_{r}^{*}\right)$. Then $\left(h_{i}\right) \geqq_{p}\left(g_{i}\right)$. Also $g_{i}^{*}=f_{i}^{*}$ and $h_{i}^{*}=e_{i}^{*}$ for $i=1, \cdots, r$. So $\left(u_{1}+g_{1}^{*}, \cdots, u_{r}+g_{r}^{*}\right) \geqq_{p}$ $\left(b_{1}, \cdots, b_{r}\right)$ with $\left(b_{1}, \cdots, b_{r}\right) \prec\left(h_{i}^{*}\right)$. By induction on $k\left(u_{1}, \cdots, u_{r}\right) \geqq_{p}$ $\left(c_{1}, \cdots, c_{r}\right)$ for some $\left(c_{1}, \cdots c_{r}\right) \prec\left(h_{1}^{*}-g_{1}^{*}, \cdots, h_{r}^{*}-g_{r}^{*}\right)$. Also by induction on $k$, since $\left(u_{r+1}, \cdots, u_{k}\right)+\left(f_{r+1}^{*}, \cdots, f_{k}^{*}\right) \geqq_{p}\left(b_{r+1}, \cdots, b_{k}\right)$ for 
$\left(b_{r+1}, \cdots, b_{k}\right) \prec\left(e_{r+1}^{*}, \cdots, e_{k}^{*}\right)$ there is a $k-r$-tuple $\left(c_{r+1}, \cdots, c_{k}\right)$ such that $\left(c_{r+1}, \cdots, c_{k}\right) \prec\left(\left(e_{r+1}-f_{r+1}\right)^{*}, \cdots,\left(e_{k}-f_{k}\right)^{*}\right)$ and $\left(u_{r+1}, \cdots, u_{k}\right) \geqq_{p}$ $\left(c_{r+1}, \cdots, c_{k}\right)$. But then $\left(u_{i}\right) \geqq_{p}\left(c_{i}\right)$ with $\left(c_{i}\right) \prec\left(\left(e_{i}-f_{i}\right)^{*}\right)$. Hence we may assume that $\sum_{1}^{r} b_{i}<\sum_{1}^{r} e_{i}^{*}$ for any $r<k$.

If $\left(b_{i}\right)=\left(u_{i}+f_{i}^{*}\right)$, then $\left(u_{i}\right)=\left(b_{i}-f_{i}^{*}\right)$ and $\left(u_{i}\right) \prec\left(\left(e_{i}-f_{i}\right)^{*}\right)$. So suppose there exists some $i$ such that $b_{i}<u_{i}+f_{i}^{*}$. Let $i_{0}$ be the first such $i$. Then for any $j, 1 \leqq j \leqq i_{0}-1, b_{j}=u_{j}+f_{j}^{*}$ and by the $l$-maximality of $\left(b_{i}\right)$, either $b_{i_{0}-1}=b_{i_{0}}, i_{0}=1$, or if $b_{i_{0}-1}>b_{i_{0}}$, then for all $q>i_{0}, b_{q}=0$ since otherwise we could perform a mototone $(1,-1)$-change on $\left(b_{i}\right)$. Moreover, by the $p$-minimality of $\left(u_{i}\right), u_{i_{0}}$ cannot be reduced in any coordinate so that $u_{i_{0}}+f_{i_{0}}^{*}>b_{i_{0}}$ implies that $u_{i_{0}}=0$. Since $f_{i}^{*}$ is either 0 or 1 for each $i$, we conclude that $1=f_{i_{0}}>b_{i_{0}}=0$. Hence $i_{0} \neq 1$ (for if $i_{0}=1$ then $\left(b_{i}\right)=(0, \cdots, 0)$ ) and $b_{i_{0}} \neq b_{i_{0}-1}$ (for if $b_{i_{0}-1}=b_{i_{0}}$, then $b_{i_{0}-1}=0<1+u_{i_{0}-1}=f_{i_{0}-1}^{*}+u_{i_{0}-1}$ contradicting the choice of $i_{0}$ ). So $b_{i_{0}-1}>b_{i_{0}}$ and $q>i_{0}$ implies that $b_{q}=0$. Since $e_{i_{0}}^{*}>f_{i_{0}}^{*}, e_{i_{0}}^{*}>0$. Therefore $e_{1}^{*}+\cdots+e_{i_{0}-1}^{*}<e_{1}^{* *}=$ $b_{1}^{*}=b_{1}+\cdots+b_{i_{0}-1} \leqq e_{1}^{*}+\cdots+e_{i_{0}-1}^{*}$, a contradiction. Therefore the $i_{0}$ does not exist and the theorem is proved.

COROLLARY 6.12. Each product of the elementary symmetric elements is join principal in $P\left(a_{i}\right)$.

Proof. If $A, B$, and $C$ are in $P\left(a_{i}\right)$ with $A$ a product of the $a_{i}$ 's, then $(A B \vee C: A)=(A B: A) \vee(C: A)=B \vee(C: A)$ since $B$ and $C$ are joins of join irreducibles in $P\left(a_{i}\right)$.

REMARK. In general if $A$ and $B$ are join irreducible in $P\left(a_{i}\right)$, $A: B$ is not join irreducible; for example, $a_{2}^{2}: a_{1}=a_{2}^{2} \vee a_{3}$ in $P\left(a_{1}, a_{2}, a_{3}\right)$. Of course the residual $A: B$ is join irreducible if $A=C B$ for some $C$ in $P\left(a_{i}\right)$.

7. Principal elements in $P\left(a_{i}\right)$. In general a product of elementary symmetric elements in $P\left(a_{i}\right)$ is not a principal element in $P\left(a_{i}\right)$. In particular $a_{1}$ is not weak meet principal if $k>1$ since from $\S 2\left(a_{k}: a_{1}\right)=a_{k}$ so $\left(a_{k}: a_{1}\right) a_{1}=a_{1} a_{k}$ while $a_{k} \wedge a_{1}=a_{k} \neq a_{1} a_{k}$. However, there is a nontrivial principal element, $a_{k}$, in $P\left(a_{i}\right)$ since $a_{k}$ is a principal element in $R L\left(A_{i}\right)$. We show that $a_{k}$ and its powers are the only nontrivial principal elements in $P\left(a_{i}\right)$.

A $\Pi$-domain is a multiplicative lattice, $L^{\prime}$, which contains a subset, $S$, of elements of $L^{\prime}$ which generates $L^{\prime}$ under joins such that every element of $S$ is a product of prime elements and in which 0 is a prime element $[1, \S 4]$.

THEOREM 7.1. $P\left(a_{i}\right)$ is a $I$-domain in which the only principal 
elements are $0, a_{k}^{t}$ for $t \geqq 1$, and $I$.

Proof. 0 is a prime element in $P\left(a_{i}\right)$ since 0 is a prime element in $R L\left(A_{i}\right)$. Moreover, $P\left(a_{i}\right)$ is a multiplicative lattice which is generated under joins by products of the elementary symmetric elements.

If $A$ and $B$ are joins of products of the $a_{i}$ 's such that $A \nsubseteq a_{j}$ and $B \leqq a_{j}$ for a fixed $j, 1 \leqq j \leqq k$, then there are products $\Pi a_{i}^{e_{i}}$ and $\Pi a_{i}^{f_{i}}$ in the minimal bases in $P\left(a_{i}\right)$ respectively such that $\Pi a_{i}^{e_{i}} \not \leq a_{j}$ and $\Pi a_{i}^{f_{i}} \not \$ a_{j}$. Then there exist $\left(r_{i}\right) \prec\left(e_{i}^{*}\right)$ and $\left(s_{i}\right) \prec\left(f_{i}^{*}\right)$ such that both $\left(r_{i}\right)$ and $\left(s_{i}\right)$ have fewer than $j$ nonzero integers. By symmetry $\left(r_{i}^{\prime}\right)$ and $\left(s_{j}^{\prime}\right)$, the monotone representatives of $\left(r_{i}\right)$ and $\left(s_{i}\right)$ are in the minimal bases for $\Pi a_{i}^{e_{i}}$ and $\Pi a_{i}^{f_{i}}$ respectively and $\left(r_{i}^{\prime}\right)+\left(s_{i}^{\prime}\right)$ has fewer than $j$ nonzero entries. Therefore $\Pi A_{i}^{r^{\prime}} \cdot \Pi A_{i^{s^{\prime}}} \geqq a_{j}$ and hence $A B \nsubseteq a_{j}$. Hence $a_{j}$ is a prime element in $P\left(a_{i}\right)$.

0 and $I$ are principal elements in $P\left(a_{i}\right)$. The fact that any weak meet principal element in $P\left(a_{i}\right)$ is join irreducible follows from [1, Theorem 1.2]. So in $P\left(a_{i}\right)$ the only nontrivial candidates for principal elements are products of the $a_{i}$ 's. Moreover, since $A B$ principal implies that $A$ is principal and $a_{1} \cdots, a_{k-1}$ are not principal elements in $P\left(a_{i}\right)$, the only principal elements in $P\left(a_{i}\right)$ are powers of $a_{k}, 0$, and $I$.

8. Remarks (multiplicative lattices), Elements in $R L\left(A_{i}\right)$ and $P\left(a_{i}\right)$ are joins of unique products of their generators. Moreover, both of these multiplicative lattices have a partial order which naturally induces an order on $k$-tuples associated with their exponent $k$-tuples. If we define $\phi: R L\left(A_{i}\right) \rightarrow P\left(a_{i}\right)$ by sending $A_{i}$ to $a_{i}$ for each $i$ and extending $\phi$ via products and joins, we see that $\phi$ is a join-morphism which preserves products, primes, and join principalness. However $R L\left(A_{i}\right)$ is the lattice of ideals of a semigroup while $P\left(a_{i}\right)$ is not [1]. The problem in $P\left(a_{i}\right)$ is the absence of weak meet principal generators.

In $P\left(a_{i}\right)(k>1)$ every prime contains the only principal prime element, $a_{k}$.

9. Remarks (partitions of integers). Brylawski [4] has studied certain sublattices of $P\left(a_{i}\right)$. He defined $L_{k}$ to be the lattice of monotone partitions of $k$ of length $k$. Extending Brylawski's notation, we write $L_{n}^{k}$ for the lattice of monotone partitions of $n$ with the understanding that the last $n-k$ entries are zero if $n \geqq k$ and the last $k-n$ entries are zero if $n<k$.

For $\mathfrak{B}$, $\mathfrak{E} \subseteq P\left(a_{i}\right)$, we write $\mathfrak{B}$. $\mathfrak{E}$ for $\{A B \mid A \in \mathfrak{B}$ and $B \in \mathfrak{F}\}$.

Proposition 9.1. $P\left(a_{i}\right)$ is the disjoint union of isomorphic 
images of $L_{n}^{k}, \bigcup_{n \geqq 0 \text { or } n=\infty} \psi\left(L_{n}^{k}\right)$ where we set $L_{0}^{k}=\{(0, \cdots, 0)\}$ and $L_{\infty}^{k}=\{(\infty, \cdots, \infty)\}$ with $\psi\left(s_{1}, \cdots, s_{k}\right)=\Pi a_{i}^{s_{i}-s_{i+1}}$ and $s_{k+1}=0$. Moreover $\psi\left(L_{n_{1}}^{k}\right) \cdot \psi\left(L_{n_{2}}^{k}\right)=\psi\left(L_{n_{1}+n_{2}}^{k}\right)$ if $n_{1}, n_{2} \geqq k$.

Proof. That $L_{n}^{k}$ and $\psi\left(L_{n}^{k}\right)$ are isomorphic as lattices follows from Theorem 5.2 and the fact that dom restricted to $L_{n}^{k}$ is simply majorization. Clearly $\psi\left(L_{n_{1}}^{k}\right) \cap \psi\left(L_{n_{2}}^{k}\right)=\phi$ for $n_{1} \neq n_{2}$ and $\bigcup_{n} \psi\left(L_{n}^{k}\right)=$ $P\left(a_{i}\right)$ if we agree $\psi\left(L_{0}^{k}\right)=I$ and $\psi\left(L_{\infty}^{k}\right)=0$. That $\psi\left(L_{n_{1}}^{k}\right) \cdot \psi\left(L_{n_{2}}^{k}\right)=$ $\psi\left(L_{n_{1}+n_{2}}^{k}\right)$ if $n_{1}, n_{2} \geqq k$ follows from the addition of exponents of the $a_{i}$ 's in $P\left(a_{i}\right)$ under multiplication.

10. Remarks (symmetric elements). We asked whether the multiplicative sublattice of symmetric elements, $\mathfrak{N}(\S 1)$ can be generated naturally by a proper subset of generators. We note here that a large subset of $\mathfrak{R}$ does not generate $\mathfrak{R}$ under products and joins.

If $\left(s_{i}\right)$ is a $k$-tuple of nonzero integers then in $R L\left(A_{i}\right), A_{1}^{s_{1}}$, $A_{2}^{s_{2}}, \cdots, A_{k}^{s_{k}}$ is a prime sequence [6]. So $P\left(a_{1}^{\left(s_{1}\right)}, \cdots, a_{k}^{\left(s_{k}\right)}\right)$ is a $\Pi$ domain isomorphic with $P\left(a_{i}\right)$ where $a_{i}^{\left(s_{i}\right)}$ is the $i$ th elementary symmetric element in $A_{1}^{s_{1}}, \cdots, A_{k}^{s_{k}}$. Moreover, in terms of the $A_{i}$ 's, $\Pi_{i=1}^{k}\left(a_{i}^{\left(s_{i}\right)}\right)^{e_{i}}=\left\{\Pi A_{i}^{t_{i}} \mid t_{i}=s_{i} r_{i}\right.$ for some $\left.\left(r_{i}\right) \prec\left(e_{i}^{*}\right)\right\}$. Elements in $P\left(a_{i}^{\left(s_{i}\right)}\right)$ are all symmetric. However, $\bigcup_{\left(s_{i}\right)} P\left(a_{i}^{\left(s_{i}\right)}\right)$ generates a proper subset of $\mathfrak{R}$. For example, if $C=A_{1}^{5} A_{2}^{3} A_{3}$ in $R L\left(A_{1}, A_{2}, A_{3}\right)$, then $\mathrm{V}_{g \in S_{3}} C^{g}$ is a symmetric element which is not the join of products of any of the $a_{i}^{\left(s_{i}\right)}$ 's.

\section{REFERENCES}

1. D. D. Anderson, R-lattices, Algebra Universalis, 6 (1976), 131-145.

2. G. Birkhoff, Lattice theory, (Third Ed.), Amer. Math. Soc., 1967.

3. K. P. Bogart, Distributive local Noether lattices, Michigan Math. J., 16 (1969), 215-223.

4. Thomas Brylawski, The lattice of integer partitions, Discrete Math., 6 (1973), 201-219.

5. D. Gale, $A$ theorem on flows in networks, Pacific J. Math., 7 (1957), 1073-1082.

6. E. W. Johnson, and M. Detlefsen, Prime sequences and distributivity in local Noether lattices, Fund. Math., 86 (1974), 149-156.

7. H. J. Ryser, Combinatorial mathematics, Math. Assoc. Amer., 1963.

8. G. Szasz, Lattice Theory, Academic Press, 1963.

9. M. Ward, and R. P. Dilworth, Residuated lattices, Trans. Amer. Math. Soc., 45 (1939), 335-354.

Received June 23, 1977. 



\title{
PACIFIC JOURNAL OF MATHEMATICS
}

\section{EDITORS}

RICHARD ARENS (Managing Editor)

University of California

Los Angeles, CA 90024

Charles W. Curtis

University of Oregon

Eugene, OR 97403

C. C. MOORE

University of California

Berkeley, CA 94720
J. DUGUNDJI

Department of Mathematics

University of Southern California

Los Angeles, CA 90007

R. Finn and J. Milgram

Stanford University

Stanford, CA 94305

\section{ASSOCIATE EDITORS}
E. F. BECKENBACH
B. H. Neumann
F. WOLF
K. YosHidA

\section{SUPPORTING INSTITUTIONS}

\author{
UNIVERSITY OF BRITISH COLUMBIA \\ CALIFORNIA INSTITUTE OF TECHNOLOGY \\ UNIVERSITY OF CALIFORNIA \\ MONTANA STATE UNIVERSITY \\ UNIVERSITY OF NEVADA, RENO \\ NEW MEXICO STATE UNIVERSITY \\ OREGON STATE UNIVERSITY \\ UNIVERSITY OF OREGON
}

\author{
UNIVERSITY OF SOUTHERN CALIFORNIA \\ STANFORD UNIVERSITY \\ UNIVERSITY OF HAWAII \\ UNIVERSITY OF TOKYO \\ UNIVERSITY OF UTAH \\ WASHINGTON STATE UNIVERSITY \\ UNIVERSITY OF WASHINGTON
}

The Supporting Institutions listed above contribute to the cost of publication of this Journal, but they are not owners or publishers and have no responsibility for its content or policies.

Mathematical papers intended for publication in the Pacific Journal of Mathematics should be in typed form or offset-reproduced, (not dittoed), double spaced with large margins. Please do not use built up fractions in the text of the manuscript. However, you may use them in the displayed equations. Underline Greek letters in red, German in green, and script in blue. The first paragraph or two must be capable of being used separately as a synopsis of the entire paper. Items of the bibliography should not be cited there unless absolutely necessary, in which case they must be identified by author and journal, rather than by item number. Manuscripts, in triplicate, may be sent to any one of the editors. Please classify according to the scheme of Math. Reviews, Index to Vol. 39. All other communications should be addressed to the managing editor, or Elaine Barth, University of California, Los Angeles, California, 90024.

50 reprints to each author are provided free for each article, only if page charges have been substantially paid. Additional copies may be obtained at cost in multiples of 50 .

The Pacific Journal of Mathematics is issued monthly as of January 1966. Regular subscription rate: $\$ 72.00$ a year (6 Vols., 12 issues). Special rate: $\$ 36.00$ a year to individual members of supporting institutions.

Subscriptions, orders for numbers issued in the last three calendar years, and changes of address should be sent to Pacific Journal of Mathematics, P.O. Box 969, Carmel Valley, CA 93924, U.S.A. Older back numbers obtainable from Kraus Periodicals Co., Route 100, Millwood, NY 10546.

PUBLISHED BY PACIFIC JOURNAL OF MATHEMATICS, A NON-PROFIT CORPORATION

Printed at Kokusai Bunken Insatsusha (International Academic Printing Co., Ltd.). 8-8, 3-chome, Takadanobaba, Shinjuku-ku, Tokyo 160, Japan.

Copyright (C) 1978 by Pacific Journal of Mathematics Manufactured and first issued in Japan 


\section{Pacific Journal of Mathematics}

Vol. 77, No. $2 \quad$ February, 1978

Graham Donald Allen, Duals of Lorentz spaces ................... 287

Gert Einar Torsten Almkvist, The number of nonfree components in the decomposition of symmetric powers in characteristic p .......... 293

John J. Buoni and Bhushan L. Wadhwa, On joint numerical ranges ...... 303

Joseph Eugene Collison, Central moments for arithmetic functions . . . . . . 307

Michael Walter Davis, Smooth G-manifolds as collections of fiber

bundles ........................................ 315

Michael E. Detlefsen, Symmetric sublattices of a Noether lattice......... 365

David Downing, Surjectivity results for $\phi$-accretive set-valued

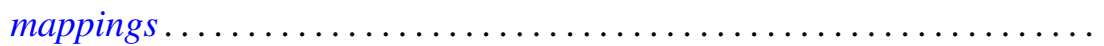

David Allyn Drake and Dieter Jungnickel, Klingenberg structures and partial designs. II. Regularity and uniformity ................. 389

Edward George Effros and Jonathan Rosenberg, $C^{*}$-algebras with approximately inner flip .......................... 417

Burton I. Fein, Minimal splitting fields for group representations. II. . . . . 445

Benjamin Rigler Halpern, A general coincidence theory ............. 451

Masamitsu Mori, A vanishing theorem for the mod $p$ Massey-Peterson spectral sequence ................................ 473

John C. Oxtoby and Vidhu S. Prasad, Homeomorphic measures in the

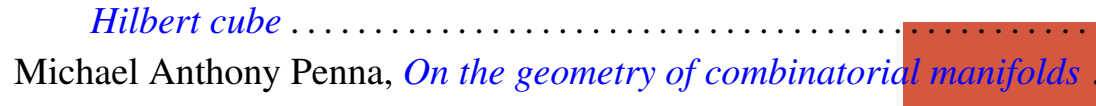

Robert Ralph Phelps, Gaussian null sets and differentiability of Lipschitz map on Banach spaces........................

Herbert Silverman, Evelyn Marie Silvia and D. N. Telage, Locally univalent functions and coefficient distortions...

Donald Curtis Taylor, The strong bidual of $\Gamma(K)$

Willie Taylor, On the oscillatory and asymptotic behavior of solutions of fifth order selfadjoint differential equations ...........

Fu-Chien Tzung, Sufficient conditions for the set of Hausdorff compactifications to be a lattice. 